
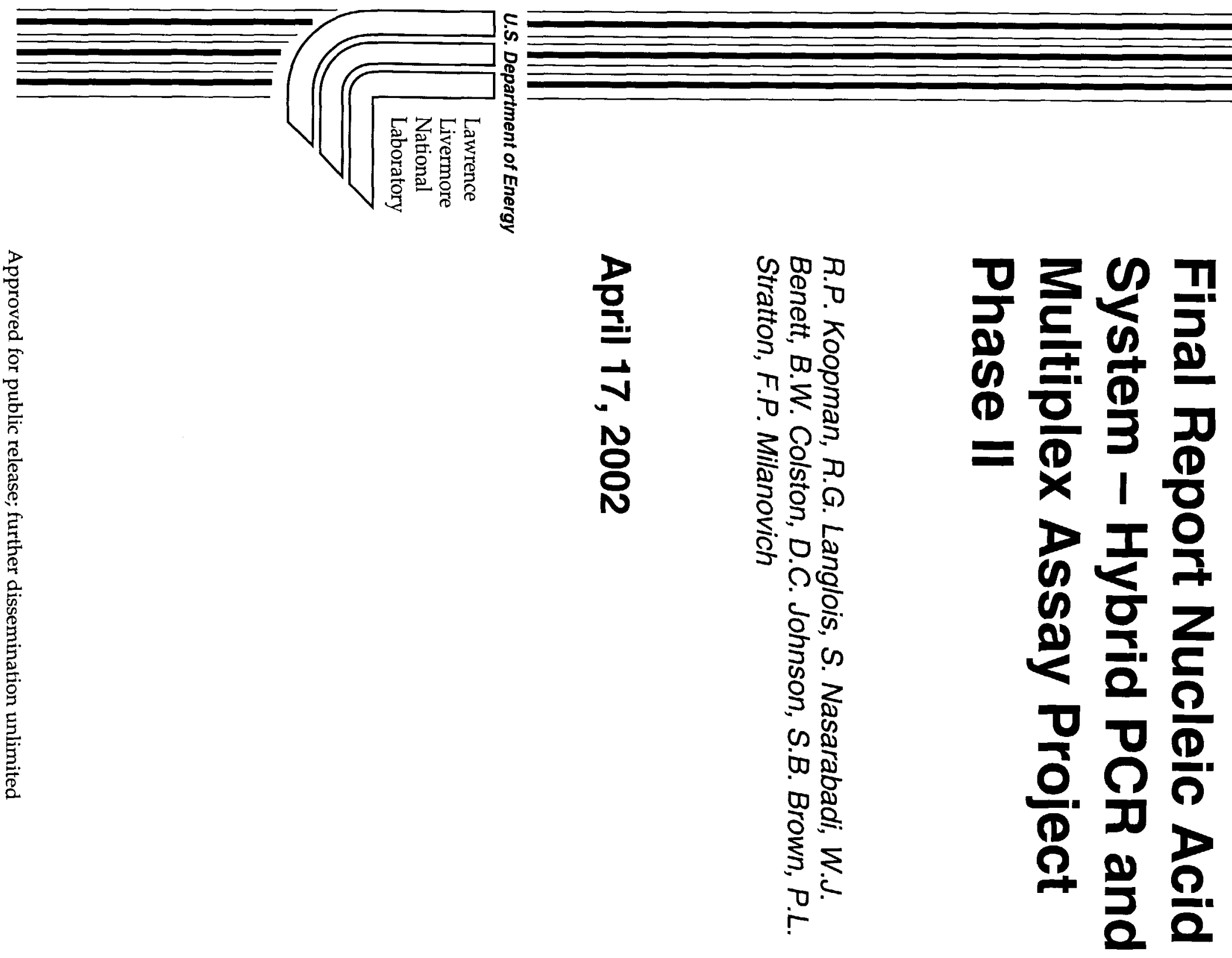


\section{DISCLAIMER}

This document was prepared as an account of work sponsored by an agency of the United States Government. Neither the United States Government nor the University of California nor any of their employees, makes any warranty, express or implied, or assumes any legal liability or responsibility for the accuracy, completeness, or usefulness of any information, apparatus, product, or process disclosed, or represents that its use would not infringe privately owned rights. Reference herein to any specific commercial product, process, or service by trade name, trademark, manufacturer, or otherwise, does not necessarily constitute or imply its endorsement, recommendation, or favoring by the United States Government or the University of California. The views and opinions of authors expressed herein do not necessarily state or reflect those of the United States Government or the University of California, and shall not be used for advertising or product endorsement purposes.

This work was performed under the auspices of the U. S. Department of Energy by the University of California, Lawrence Livermore National Laboratory under Contract No. W-7405-Eng-48.

This report has been reproduced directly from the best available copy.

Available electronically at http://www.doc.gov/bridge

Available for a processing fee to U.S. Department of Energy

And its contractors in paper from

U.S. Department of Energy

Office of Scientific and Technical Information

P.O. Box 62

Oak Ridge, TN 37831-0062

Telephone: (865) 576-8401

Facsimile: (865) 576-5728

E-mail: reports@adonis.osti.gov

Available for the sale to the public from

U.S. Department of Commerce

National Technical Information Service

5285 Port Royal Road

Springfield, VA 22161

Telephone: (800) 553-6847

Facsimile: (703) 605-6900

E-mail: orders@ntis.fedworld.gov

Online ordering: http://www.ntis.gov/ordering.htm

OR

Lawrence Livermore National Laboratory

Technical Information Department's Digital Library

http://www.llnl.gov/tid/Library.html 


\title{
Final Report \\ Nucleic Acid System - Hybrid PCR and Multiplex Assay Project \\ Phase 2
}

\author{
Ronald P. Koopman, Richard G. Langlois, Shanavaz Nasarabadi, \\ William J. Benett, Billy W. Colston, David C. Johnson, Steve B. Brown, \\ Paul L. Stratton, Fred P. Milanovich
}

April 17, 2002

\section{Project Objective}

This report covers phase 2 (year 2) of the Nucleic Acid System - Hybrid PCR and Multiplex Assay project. The objective of the project is to reduce to practice the detection and identification of biological warfare pathogens by the nucleic acid recognition technique of PCR (polymerase chain reaction) in a multiplex mode using flow cytometry. The Hybrid instrument consists of a flow-through PCR module capable of handling a multiplexed PCR assay, a hybridizing module capable of hybridizing multiplexed PCR amplicons and beads, and a flow cytometer module for bead-based identification, all controlled by a single computer. Multiplex immunoassay using bead-based Luminex flow cytometry is available, allowing rapid screening for many agents. PCR is highly specific and complements and verifies immunoassay. It can also be multiplexed and detection provided using the bead-based Luminex flow cytometer. This approach allows full access to the speed and 100-fold multiplex capability of flow cytometry for rapid screening as well as the accuracy and specificity of PCR.

This project has two principal activities: (1) Design, build and test a prototype hybrid PCR/flow cytometer with the basic capabilities for rapid, broad spectrum detection and identification, and (2) Develop and evaluate multiplex flow analysis assay protocols and reagents for the simultaneous detection of PCR products.

This project requires not only building operationally functional instrumentation but also developing the chemical assays for detection of priority pathogens. This involves development and evaluation of multiplex flow analysis assay protocols and reagents for the simultaneous detection of PCR products.

\section{Project Context}

There are several related projects ongoing at LLNL. The development and testing of PCR and DNA analysis chemistry in the Biology and Biotechnology Research Program will provide supporting expertise and capabilities. There is a large DOE funded project to build and demonstrate an autonomous pathogen detection system (APDS) involving unattended, automatic sample collection, preparation, fluidic transport, pathogen identification and reporting. APDS provides much fundamental technology development that is of direct benefit to this project. There is an internally funded laboratory initiative for new concept bio-detection that will provide complimentary, but not competing, technology development. 
In addition, $\mathrm{CMO}$ is sponsoring a supplementary project to advance the fluidics of bead handling, in line spore disruption, and use of lyophilized reagents and has sponsored an industry directed sample preparation project monitored by LLNL.

\section{Background}

This project is a logical follow-on to eight years of technology development that began with LLNL internal funding under which the micro-fabricated PCR thermal chamber was conceived and developed. This was followed by a three year DARPA funded project (1993-96) that resulted in a suitcase sized miniature PCR instrument that was successfully demonstrated at JFT III in Sep 96. In 1998 CMO funded design and construction of a field hardened 10 chamber PCR instrument with 2-plex capability which was delivered to NMRI. In 1999 CMO funded design and construction of a four chamber, handheld instrument (HANAA), a suitcase sized 24 chamber instrument (PolyHANAA), and initial work on multiplex flow analysis using the Luminex 100 and multiplex assay reagents. In $2000 \mathrm{CMO}$ initiated phase 1 of the Hybrid project. Phase 2 of the Hybrid project builds heavily on the experience and technology that resulted from these previous projects especially the 2000 CMO funded tasks.

This program will continue to draw upon the resources and personnel (scientists, engineers and technicians) from the previous work in this area. The facilities to perform the tasks described herein include well equipped chemistry and biology laboratories, static and dynamic testing chambers, a state of the art microfabrication facility, a complete electronic design and fabrication facility, a mechanical fabrication facility, including plastic extrusions, design modeling, system engineering, PCR and nucleic acid sequencing expertise, packaging and extensive field test experience.

\section{Tasks}

Task 1a. Design a field deployable hybrid PCR and immunoassay device using a flow cytometer capable of identifying more than 10 different microorganisms from the priority target list.

Task 1b. Optimize the fluidics design from the FY00 brassboard device to improve automated bead handling and hybridization.

Task 1c. Redesign the PCR thermalcycler and optics to reduce diode background in detectors and increase sensitivity.

Task 1d. Integrate fluidics, bead handling and flow cytometer under control of one computer.

Task 1e. Build a field deployable prototype.

Task 2. Evaluate multiplex flow analysis assay approaches developed in FY00 for multiplex PCR product identification. Recommend the best approach and adapt this approach to the field deployable prototype from Task 1. 
Task 3. Conduct a series of blind tests to identify an unknown agent using the hybrid field deployable prototype in the PCR screening mode with deeply multiplexed reagents.

\section{Results}

Task 1a. Design

The Hybrid design incorporates the flow through HANAA PCR module and electronics redesigned last year for flow through operation with a Global fluidics system allowing multiplex PCR product to undergo hybridization with fluorescent beads followed by analysis in the Luminex 100 flow cytometer. PCR product remains contained within the fluidics system and hybridization with beads was automated in order to avoid contamination of the system with the large amount of DNA produced during PCR. This design approach to the hybrid is highly dependent on the capabilities of the Luminex 100, a flow cytometer with a bead set of 100 identifiably different 5 micrometer beads. Each bead is prepared with a different oligonucleotide for PCR based identification or with a different antibody for immunoassay identification.

We have resolved most hardware and software related design issues around the field deployable hybrid device. A revised specifications document (ref 3) was written and is included as an attachment. Detailed design, such as a baseline fluidics layout, drawings for the PCR amplification hardware and electronics, and data acquisition interconnects have also been determined.

\section{Tasks 1b. Optimize Fluidics}

The fluidics design ultimately relies on the exact nature of the assay steps and components. A multi-step assay, for example, with intermediate wash steps will ultimately require a bead separation device. Since the exact protocol for the assay may change with application, we have assembled individual components such as hybridization cells, bead separation devices, holding coils, and PCR amplification cells and done component level testing based on a universal assay approach which includes multiple wash steps. The current Hybrid fluidics design is shown in Figure 1.

We continued to evaluate bead separation designs. The variable, piezo-electric actuated bead trap allows a desired gap to be electronically set. This promises to be useful in bead sequestering and other screening applications. To effectively be used in this fashion, further reductions in dead volume must be attained. In addition, corrosion issues related to a current leak from the piezo-electric stack must be remedied before the flexure is coupled into the device.

The microfluidics silicon based bead separation device can yield good recovery but the repeatability is poor due to problems associated with bubbles sticking in the parallel channels employed in the design. This device still holds promise and could be redesigned as a single long channel to eliminate the problem. It is one of the few devices evaluated that gave good recoveries, at least some of the time.

With proper choice of membrane material, backing and support, it appears that an in-line filter can also be employed as a simple sequestering cell. Various filter 
media were examined with mixed results. Further work is required to explore the more promising Nuclepore filter media.

The coaxial tubular bead sequestering cell provides a simple and inexpensive solution to the bead sequestering issue. The device is easy to use. Further optimization testing and long-term performance studies are required, but this cell looks most promising. Equipped with this bead sequestering cell, assays requiring wash sequences can now be explored.

Because bead sequestration was a research project this year, we focused on a simple no-wash assay protocol for automating the sample preparation steps necessary for multiplexed PCR detection. This simple fluidics protocol was transferred to the Hybrid system.

In conjunction with Global, we have developed a single hybridization chamber (see Figure 2.) capable of rapidly cycling to the appropriate temperature. This simplifies the earlier design that relied on multiple chambers at fixed temperatures. This new component greatly simplifies the assay protocol, since it eliminates the need to move reagents between multiple chambers. This hybridization cell was successfully tested in conjunction with the new sample preparation protocol and has been incorporated into the system.

Extensive testing of our existing, post-PCR fluidics protocols was performed prior to the June visit by CMO. The results of this effort were a well characterized, automated multiplex assay. Fluidics integration of the PCR and post-PCR fluidics hardware was completed and fluidic protocols for performing amplification, transferring amplicon to the post-PCR fluidics components, and decontaminating the system were implemented.

\section{Task 1c. Redesign PCR Thermalcycler}

It was our intention to focus HANAA flow-through PCR redesign on the optical system this year, but other problems with the unit demanded attention. First, we had to modify the HANAA flow-through tubing cell. Previously, to perform a temperature calibration, a thermocouple had to be inserted into the teflon tubing, far enough to be placed in the heated region of the HANAA. This operation required some disassembly, and was very tedious and time consuming. The new modification embeded a fine thermocouple in the teflon wall of the flow-through cell. The very fine wire is not expected to interfere with the optical properties of the cell.

We continued testing and use of the HANAA thermocycler, performing multiplex amplification throughout the year. The unit experienced multiple failures during that time, to the point that it's reliability was no longer acceptable for use in the Hybrid and certainly not acceptable from a user's perspective. We explored replacing the control electronics with commercial heater controller units using feedback from the imbedded thermocouple but decided that the flowthrough PCR unit had so many problems in addition that a major redesign was required. This could not be accommodated in this years budget or schedule, so we just tried to keep the unit functioning through the blind trials. 
Task 1d. Integrate Fluidics

The existing fluidics and flow-through PCR software were integrated into a form compatible with the Graphical User Interface (GUI) used to control and monitor the Luminex 100 flow cytometer. Software control solutions for the multi-step temperature profiles required for multiplex hybridization assays were developed. LabVIEW interface software for the HANAA was required because the HANAA could not communicate directly with the GUI. This is one of the major design problems that must be fixed in a flow-through PCR redesign. This software makes the instrument fully functional and enables control of all normal operating parameters of the HANAA, (temperatures, cycles and dwell times) as well as initiating the Calibration and Run functions. The software was written to accept input from a higher level controller, however it is very cumbersome to use. Nevertheless, the LabVIEW interface software for the HANAA is complete and has been tested. Improved control and data analysis software routines have been written for Luminex 100 control. In addition, the Graphical User Interface (GUI) that controls the Luminex and Global fluidics modules was partially integrated with the HANAA control software. Completion will occur after redesign of the flow through PCR unit.

\section{Task 1e. Build Field Deployable Prototype}

The field deployable Hybrid prototype was assembled in a triple-wide, custom made Global enclosure, shown in Figure 3. This unit contains most of the functionality shown in the diagram in Figure 1. The bead trap will be added next year, when the evaluation is complete. After hardware integration and check-out was complete, the blind trial was initiated. 
Figure 1.

\section{Hybrid Fluidics Diagram}

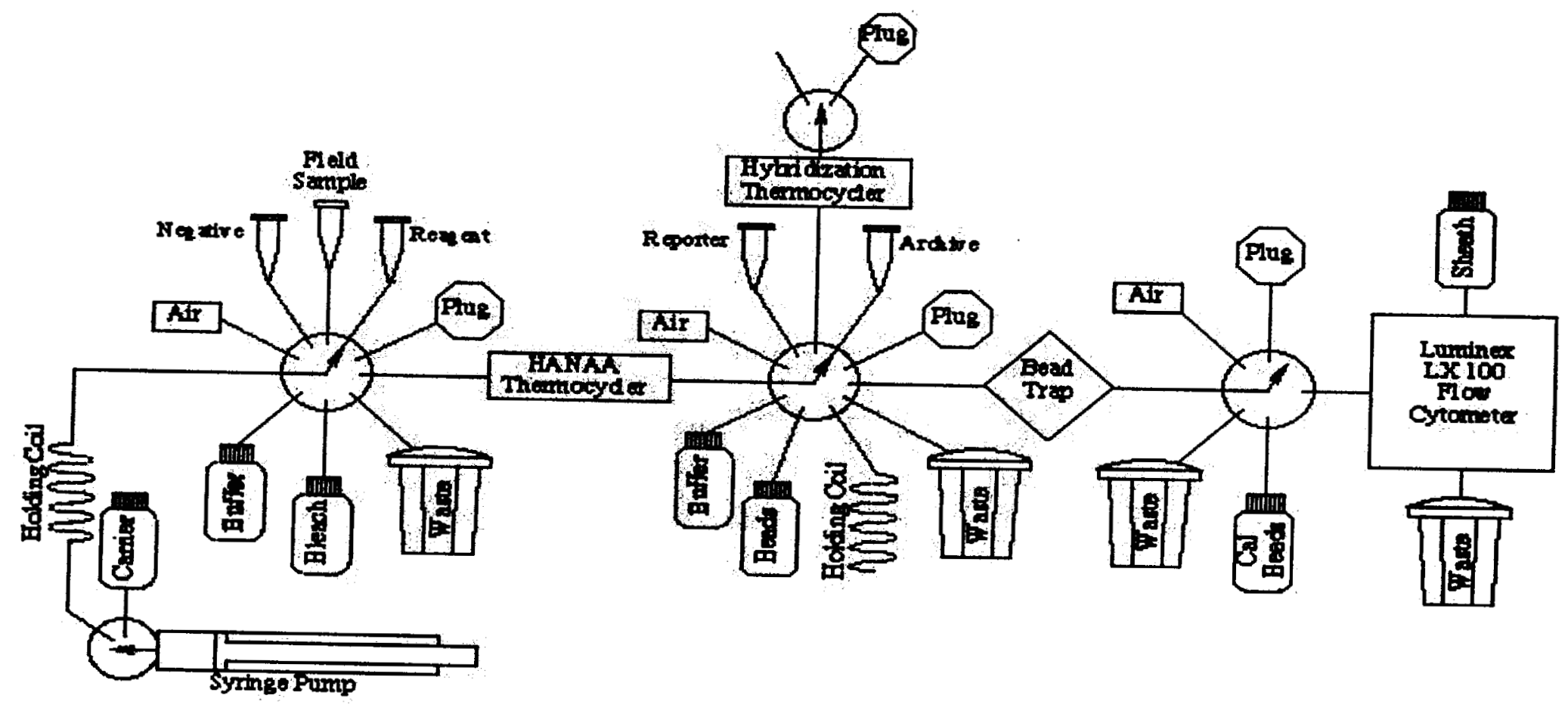


Figure 2. Hybridization thermal cycler

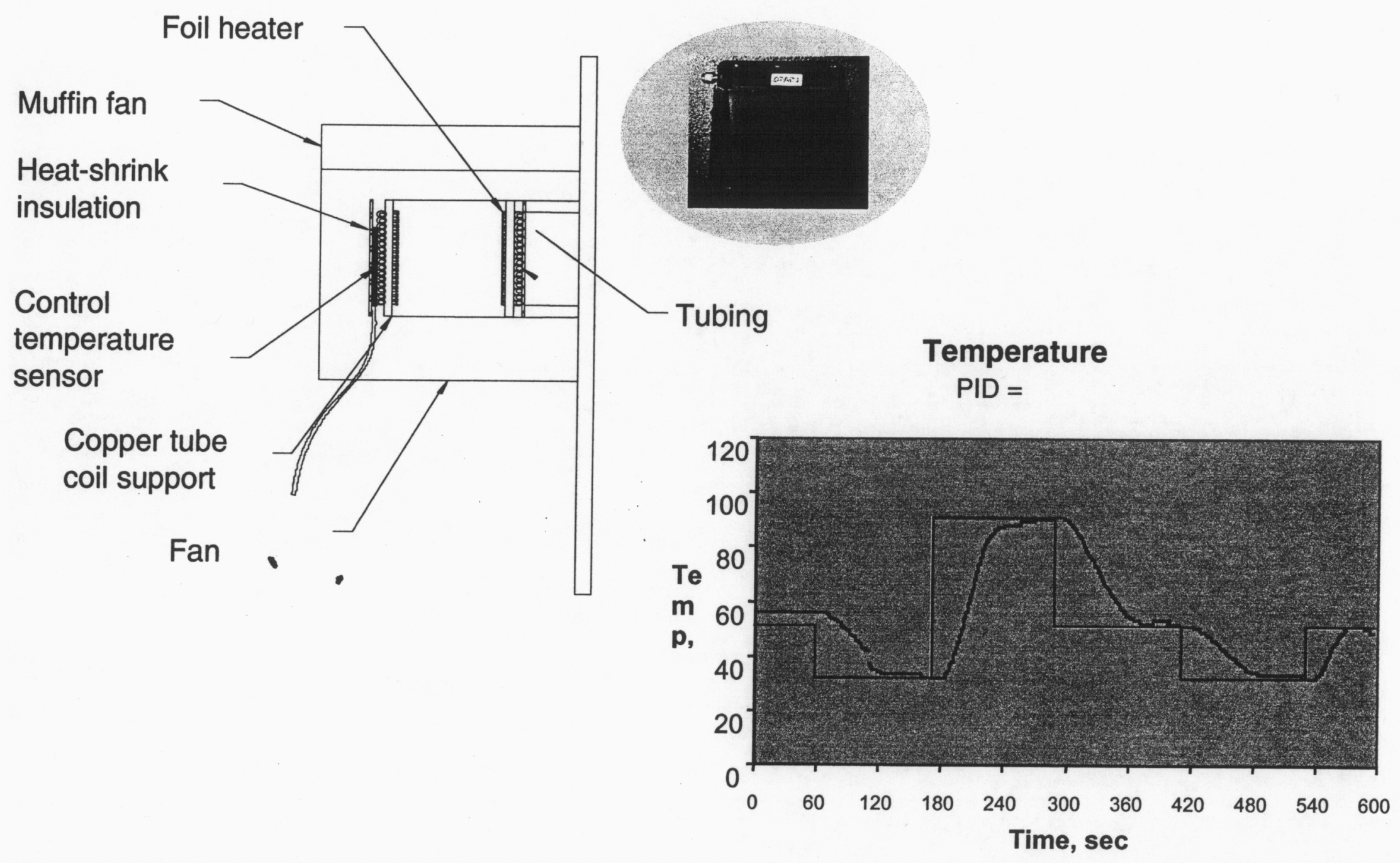


Figure 3. Complete Hybrid Instrument in laboratory

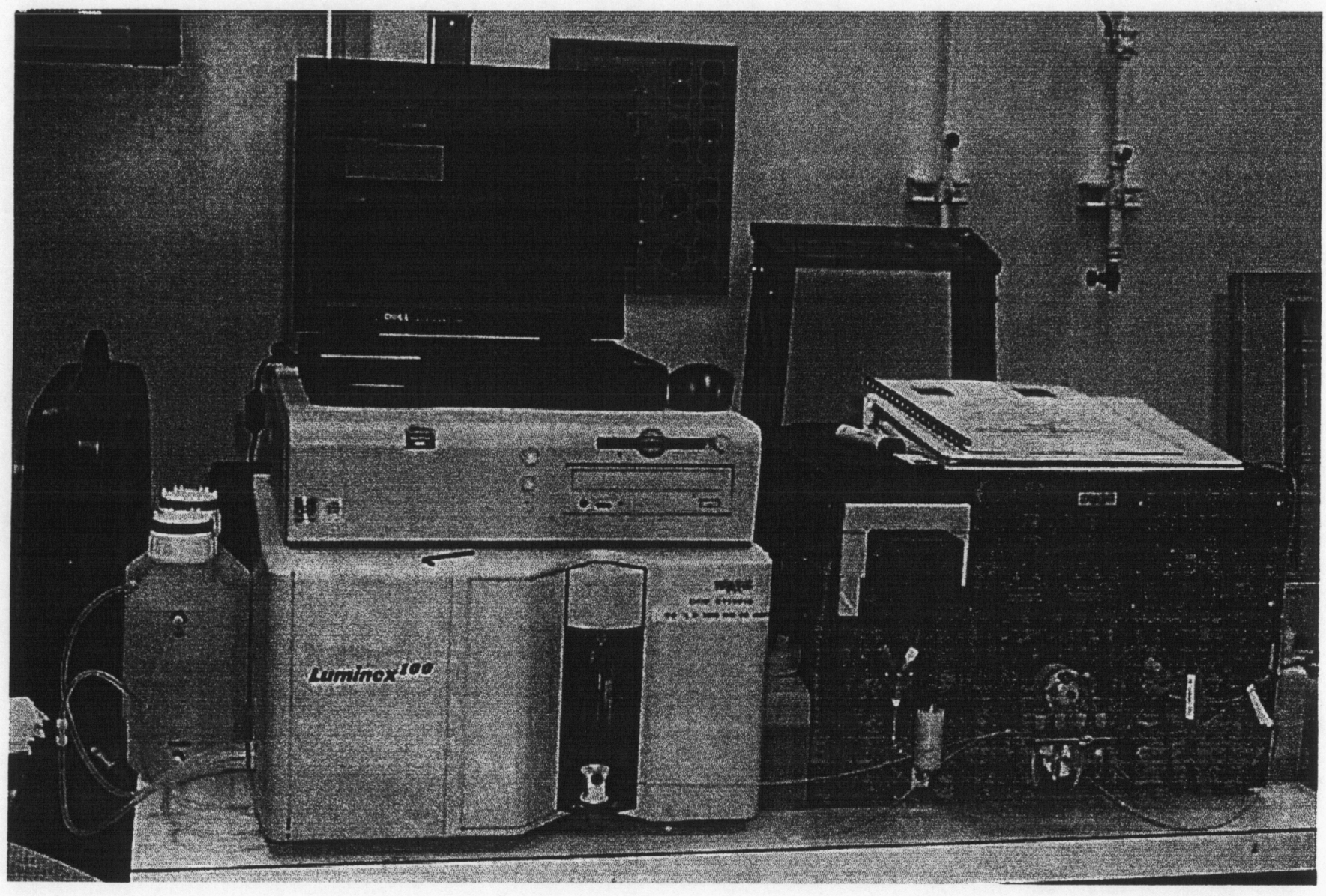


Task 2. Evaluate multiplex flow analysis assay approaches

This is the third year that we have been developing and evaluating methods for multiplex PCR amplification and product identification. Multiplex analysis allows for the simultaneous identification of multiple agents simplifying sample preparation and instrumentation. Bead-based multiplex identification methods have the additional advantage of interrogating the entire sample volume for each analysis eliminating the loss of sensitivity seen when the sample is divided for several separate analyses. Our primary focus continues to be evaluating the use of color-coded beads coated with oligonucleotides to provide a versatile platform for rapid multiplex identification. Samples containing up to 100 different bead types can be analyzed in less than one minute using flow cytometry. This approach has been successfully used in the past for the simultaneous immunochemical identification of 4 different biological simulants. We are now developing bead capture methods to allow rapid identification of PCR products from multiplex PCR amplification reactions.

We have identified the following 5 different assay strategies for bead-based multiplex PCR product identification: (1) Direct capture of fluorescently labeled PCR products; (2) Competition between PCR product and beads for a fluorescent reporter probe; (3) Taq polymerase digestion of the fluorescently-labeled reporter probe; (4) Templated enzymatic fluorescent labeling of the probe; and (5) Templated ligation of a dye olignucleotide and a target oligonucleotide. While variations on each of these strategies have been useful for bench-top laboratory analyses of DNA fragments, most of these assay protocols are too complex, or too slow for use in our Hybrid instrumentation. For this reason we have focused our efforts on strategies (1), (2), and (3), as being most likely to be successfully automated in the Hybrid instrument.

We initially evaluated the competitive hybridization strategy for identification of unlabeled PCR products. With this approach, denaturation and annealing of the PCR product with a labeled reporter probe results in a characteristic fluorescence decrease in the capture beads. The detailed methodology and results obtained using this strategy are described in detail in Reference 1. While we were successful in developing a 2-plex prototype assay using this approach, the bead labeling method was too complex and time consuming for application to the hybrid instrument.

Our next effort was to develop and evaluate a novel nuclease digestion assay conceived at LLNL. The primary advantage of this approach is that bead labeling can occur in a single step by directly hybridizing the PCR product with the capture beads. This strategy uses a fluorescently labeled internal hybridization probe that is present during PCR amplification. When the target template is present, endonulease actvity of the Taq polymerase clips the fluorescent dye from the reporter probe. The primary advantages of this approach are one-step labeling, no denaturation required, and no bead washing required. The detailed protocols and and experimental results from this assay approach applied to the simulants B.g., B.t., and E.h. are included in Reference 2 of this report. This 
approach was successfully used for 1-plex and 2-plex PCR product identification. Extension of this approach to 3 or more targets, however, was complicated by difficulties in matching amplification conditions, reducing cross-reactivity among probes, and optimizing bead labeling.

Currently we are focusing on the third strategy, direct capture of biotin-labeled PCR products. While this approach requires more steps compared with the nuclease assay, the resulting fluorescent difference between positive and negative beads is much greater than seen with the previous strategies. Figure 4 shows a schematic diagram of how PCR product is captured on to beads with the direct binding assay. Briefly, amplification is performed with a biotinylated primer so that the final PCR product contains a biotin on one end. Beads with an internal capture probe are added, then denaturation and annealing leads to bniotinylated product being bound to the beads. Finally, streptavidin-PE is added to brightly label the biotin bound to beads yielding a bright fluorescence signal when a specific PCR product is present. The detailed protocol for this assay is shown below. Total sample preparation time is $30 \mathrm{~min}$. with no wash steps required.

Protocol for the No Wash Direct Hybridization Assay

1. Aspirate $5 \mu \mathrm{l}$ of sample

2. Mix with $22 \mu$ l of Bead mix

3 . Move to hybridization cell

4. Denature @ $96^{\circ} \mathrm{C}$ for 5 minutes

5. Incubate @ $56^{\circ} \mathrm{C}$ for 5 minutes

6. Add $60 \mu 1$ of Streptavidin PE $(4 \mathrm{ng} / \mu \mathrm{l})$

7. Incubate @ room temperature for 10 minutes

8. Read in the Luminex.

The direct hybridization assay has been applied to a 3-plex analysis of the simulants B.g., B.t., and E.h. With this assay, a positive fluorescence intensity indicates the presence of a specific target. Figure 5 shows the results from multiple experiments using the three simulant targets over a period of 5 weeks. Note the dramatic reporter intensity difference between positive and negative beads. While there is some intensity variability among experiments, there remains a clear distinction between the presence and absence of each template. Finally, all permutations from 0 through 3 templates are reliably amplified and identified with this assay.

We established a subcontract with Tetracore, Inc. to extend our set of targets to 5 by adding primers and probes for the pathogens B.a. and Y.p. Tetracore designed these assays so that all PCR amplifications could be performed using the same set of thermal cycling conditions. We confirmed that all assays could be performed using the same conditions with a Taqman assay on the ABI 7700 . A complete set of custom oligos was ordered to allow us to prepare the specific reagents for our direct hybridization assay. Our initial results with a new 3-plex assay for B.a., Y.p., and E.h are shown in Figure 6. While there is still a wide 
separation between positive and negative bead intensities, balancing of the intensities among bead types was more difficult for this 3-plex assay. This 3-plex pathogen assay was used for the blind test described below. Finally, we attempted a full 5-plex assay with the simulant and pathogen assays. The results of the 5-plex assay are shown in Figure 7. Correct assay results were observed for E.h, B.t., and Y.p. A correct, but weak signal was observed for B.a., and no amplification was seen for B.g. Thus, while each of these assays individually worked under the same conditions, further fine tuning will be required to ensure that all work simultaneously in a 5-plex assay.

In summary, we have evaluated three assay strategies for bead-based identification of PCR products from multiplex PCR amplifications. While the competitive assay and Taq nuclease assay worked well for some targets, both were difficult to extend to 3 or more targets. Also, both assay strategies yielded small intensity differences between positive and negative samples. The direct hybridization assay strategy, in contrast yielded clear and reproducible intensity differences between positives and negatives. This approach was successfully used for two different 3-plex assays. Extension of this approach to 5-plex will require some additional adjustment of assay conditions. Specific areas for future improvement include optimization of bead labeling, reduction of cross-reactivity among probes, and better matching of amplification conditions. 


\section{Fig. 4 Direct capture of biotin-labeled product}

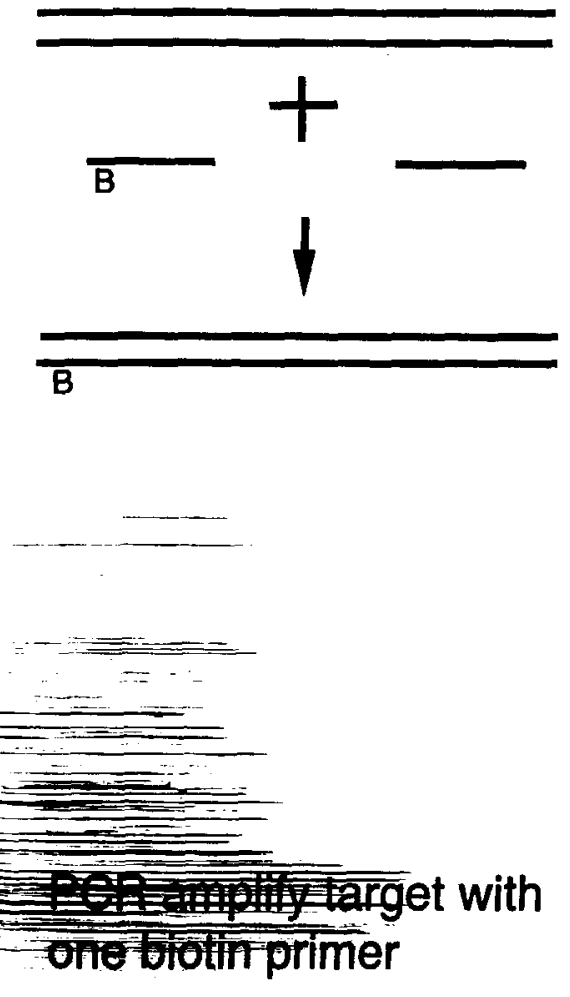

2-3 biotin per primer

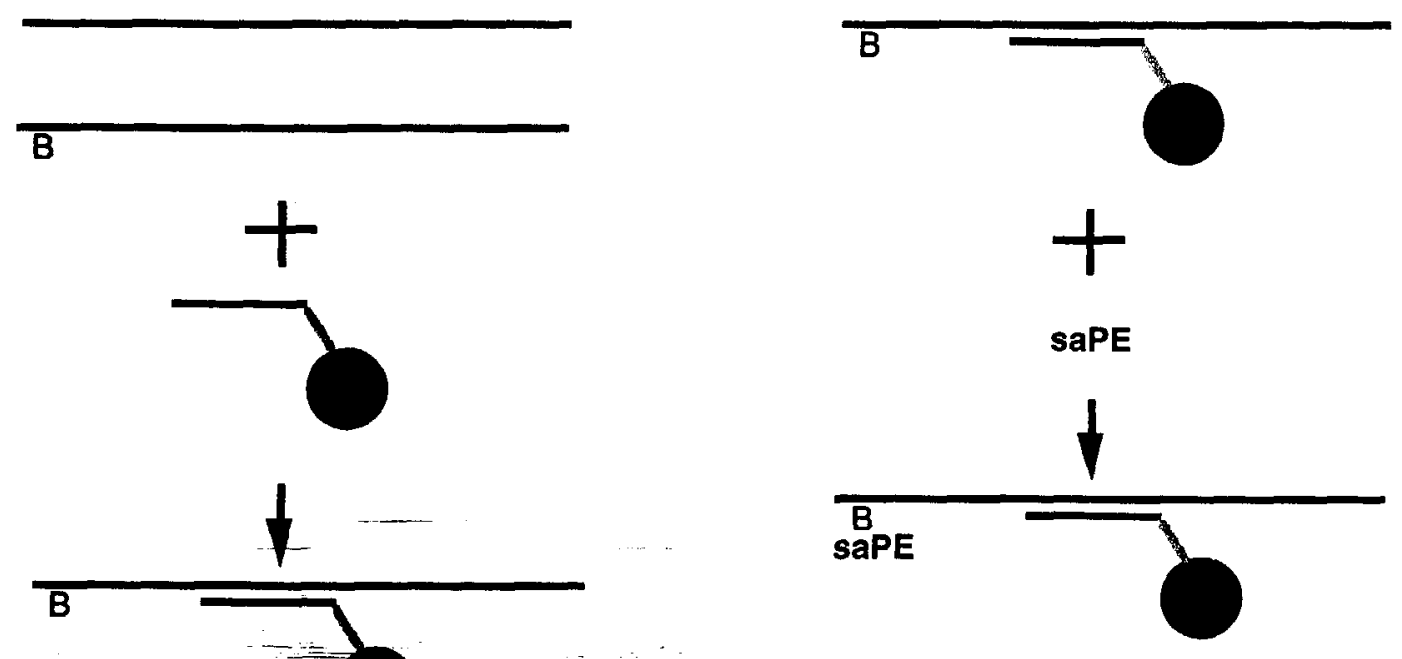

Add captur beads - Add streptavidin-PE Denaturtepioduct incubate at RT Anneal with bead

C-18 linker to bead
PE bright label

Increased Fluorescence 
Fig. 5 Mean and SD for 6 replicate analyses over 5 weeks
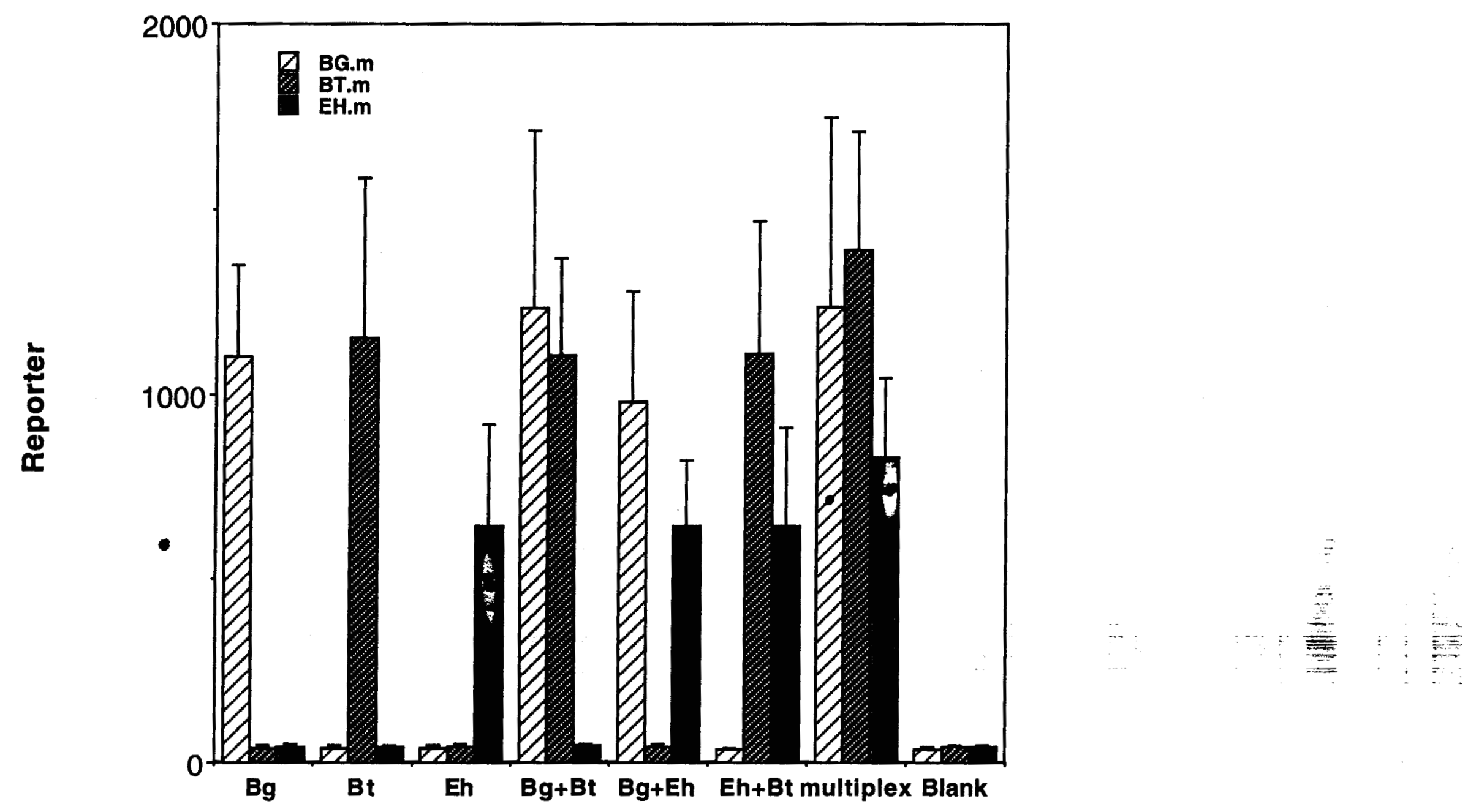

sample 
Fig. 6 3-Plex bead analysis of B.a., Y.p., and E.h.

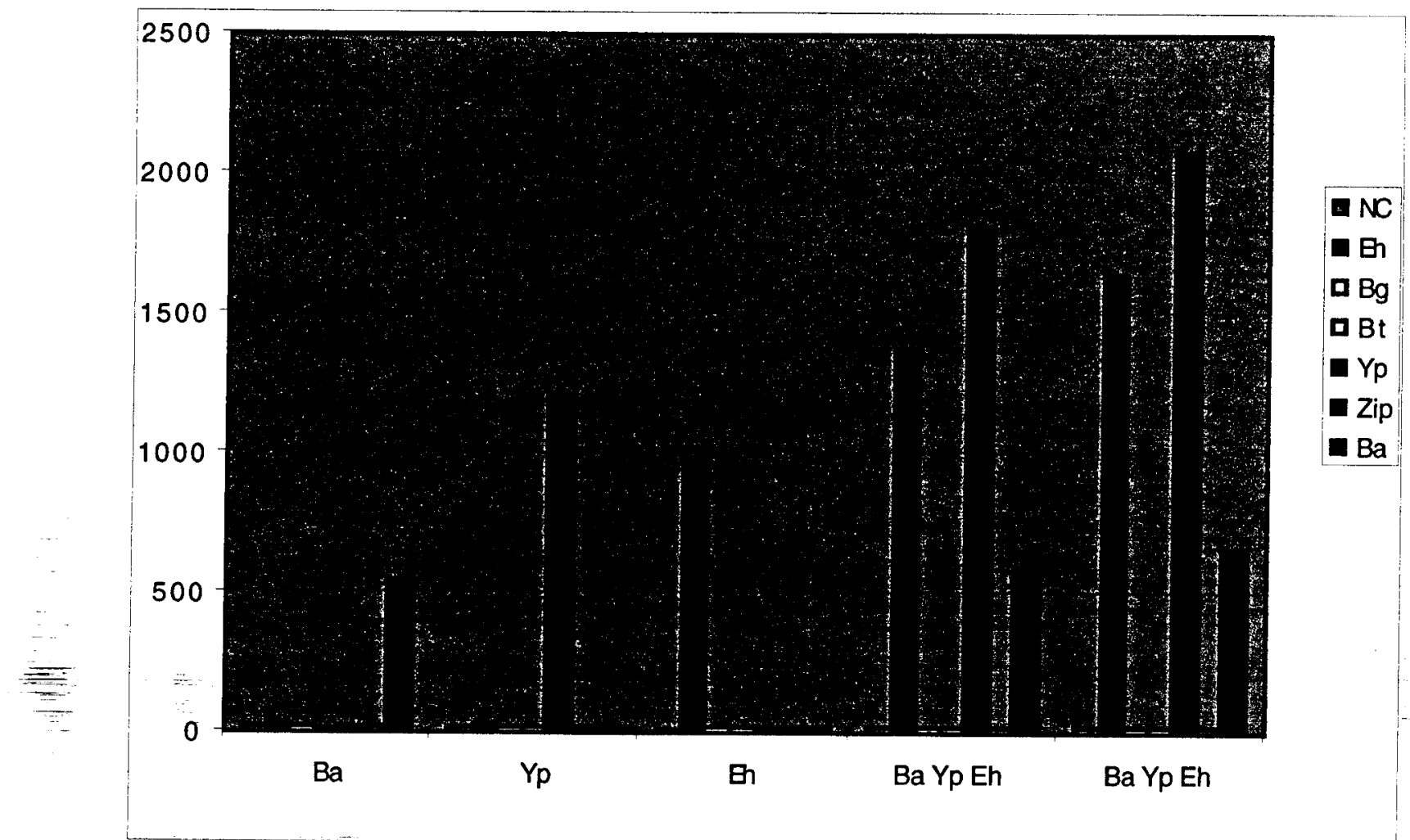


Fig. 7 5-Plex bead analysis of B.g., E.h., B.t., Y.p, and B.a.

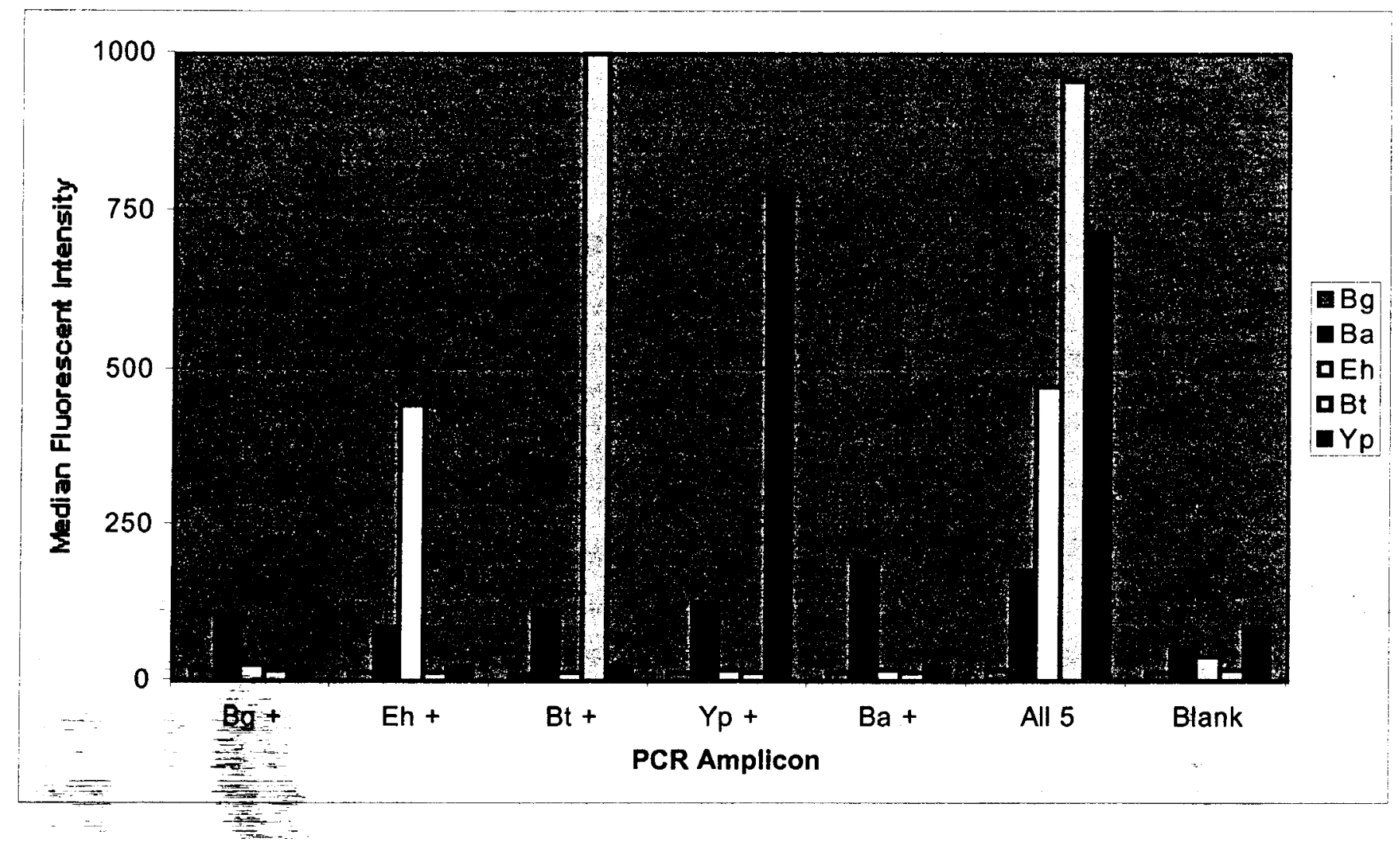

B.g. template did not amplify 
Task 3. Conduct a series of blind tests

The detailed test plan for multiplex PCR product identification with the prototype hybrid instrument is included as an attachment to this report. Briefly, a set of samples were prepared using template cells or DNA from the organisms Erwinia herbicola, Bacillus anthracus, and Yersinia pestis. The 8 samples consisted of 3 blank, 3 single-agent, and 2 multi-agent samples. The coded samples were processed sequentially through the instrument, and the true identity of the samples were not revealed until all processing was complete.

The test samples were prepared and encoded on Tues. December 4, 2001. The laboratory testing of these samples began December 5, 2001 as part of a Project Review at LLNL attended by CMO staff. Visual inspection of the Luminex results from the first samples suggested poor hybridization due to apparent errors in denaturation and annealing temperatures in the hybridization chamber. The trial was continued with an aliquot of PCR product saved from each sample to allow the hybridization step to be repeated at a later date after the hybridization chamber problem was corrected. A total of 7 samples were processed through the HANAA flow-through PCR chamber, but one sample was lost due to an over-temperature fault that damaged the flow-through chamber (see the HANAA control problems noted above). The 7 PCR product samples were stored frozen for later analysis.

Tests of the hybridization chamber using a calibrated thermocouple confirmed that there were significant variations in temperature with sample position in the chamber. Modifications to the fluidic routines yielded some improvement, but reducing the length of the coiled tubing in the device gave the best results. The heater element failed after these modifications. Finally, a new heater was purchased and installed, and the performance of the hybridization chamber was confirmed on February 12, 2002.

The frozen aliquots of the test PCR product samples were processed through the hybridization module and sent to the LX-100 for analysis. While fresh PCR products showed clear hybridization, the frozen samples yielded variable signals with high backgrounds. There was minimum concordance between predicted and expected results for these test samples ( $2 / 7$ correct). Potential sources of problems included (a) E.h. contamination of the PCR module, since E.h. is seen in all samples; (b) inconsistent amplification due to temperature problems in the HANAA module, or (c) degradation of the samples when stored frozen. A repeat test was not possible due to the heat-damaged flow-through PCR module. Further testing will be performed when we have a more stable flow-through PCR module. 
Blind test results

$\begin{array}{lll}\text { Sample \# } & \text { Observed } & \text { Truth } \\ 1 & \text { Eh Yp Ba } & \text { Blank } \\ 2 & \text { sample lost } & \text { Eh Yp Ba } \\ 3 & \text { Eh } & \text { Blank } \\ 4 & \text { Eh } & \text { Ba } \\ 5 & \text { Eh Yp Ba } & \text { Eh Yp Ba } \\ 6 & \text { Eh Yp } & \text { Blank } \\ 7 & \text { Eh } & \text { Eh } \\ 8 & \text { Eh Yp Ba } & \text { Yp }\end{array}$

\section{Deliverables}

a. System Design Specification (Task 1)

The system design specification was revised and reissued and is included as an attachment.

b. Engineering drawings and schematics (Task 1)

Because the drawing package delivered as part of Phase 1 was delivered in July, it contained an essentially complete and current set of drawings of the system. The final drawings will be delivered at the end of the next phase of the project.

c. Field deployable prototype hybrid PCR and immunoassay device (Task 1) Functionality of the field deployable Hybrid was demonstrated on December 5, 2001.

d. Technical report recommending multiplex PCR product identification approach (Task 2)

The technical report recommending the preferred approach to multiplex PCR product identification is included in the body of this report.

e. Test plan (Task 3)

The Test Plan for Multiplex PCR Product Identification with Field Deployable

Prototype Hybrid Instrument was delivered to $\mathrm{CMO}$ and is included here as an attachment.

f. Test results (Task 3)

The test results from the blind test are included in the body of this report.

g. Final technical report detailing system design and assay protocol(s)

This report satisfies that requirement

\section{Attachments and/or references}


1. Venkateswaran K, Nasarabadi S, Langlois R, Report on the Results of the Laboratory Tests of Multiplex Detection of PCR Amplicons Using the Luminex 100 Flow Analyzer, UCRL-ID 139001, May 5, 2000.

2. Final Report, Nucleic Acid System Hybrid PCR and Multiplex Assay Project, Phase 1, April 9, 2001, UCRL-ID-143781

3. The Hybrid, PCR/Flow Cytometer Pathogen Detection, Requirements and Specifications Document, February 5, 2002, Ver 2.0 (attached)

4. Test Plan for Multiplex PCR Product Identification with Field Deployable Prototype Hybrid Instrument, October 17, 2001 (attached) 


\title{
DRAFT
}

\author{
The Hybrid
}

PCR/Flow Cytometer Pathogen Detection

\section{Requirements and Specifications Document}

February 5, 2002

Ver. 2.0 


\section{EXECUTIVE SUMMARY}

The project objective is to combine advances in rapid PCR and multiplex flow analysis in a single instrument capable of multiplex pathogen and toxin detection and identification by both nucleic acid recognition and immunological bead assays. This project will reduce to practice the detection and identification of biological terrorism pathogens by the nucleic acid recognition technique of PCR in a multiplex mode using flow cytometry. This entails not only building operationally functional instrumentation but also developing the chemical assays for detection of priority pathogens. This project has two principal activities: (1) Design, build and test a hybrid PCR/flow cytometer with the basic capabilities for rapid, broad spectrum detection and identification, and (2) Develop and evaluate multiplex flow analysis assay protocols and reagents for the simultaneous detection of PCR products.

\section{SYSTEM DEVELOPMENT}

\section{Project Goals}

The goal of this project is to provide an integrated, self contained system capable of performing three primary tasks: rapid ( $<30$ minute) in-line PCR (polymerase chain reaction) based nucleic acid amplification, real time ( $<30$ minutes) in-line hybridization of PCR amplicons and Luminex beads, and rapid ( $<2$ minutes) Luminex bead based immunological assays.

\section{System Description}

This project will produce a prototype instrument, capable of demonstrating performance characteristics in a laboratory bench top setting. The instrument is not designed for autonomous operation, and only provides limited sample preparation for bead-based hybridization assays (Fig.1). All data acquisition and control will occur from a central user interface.

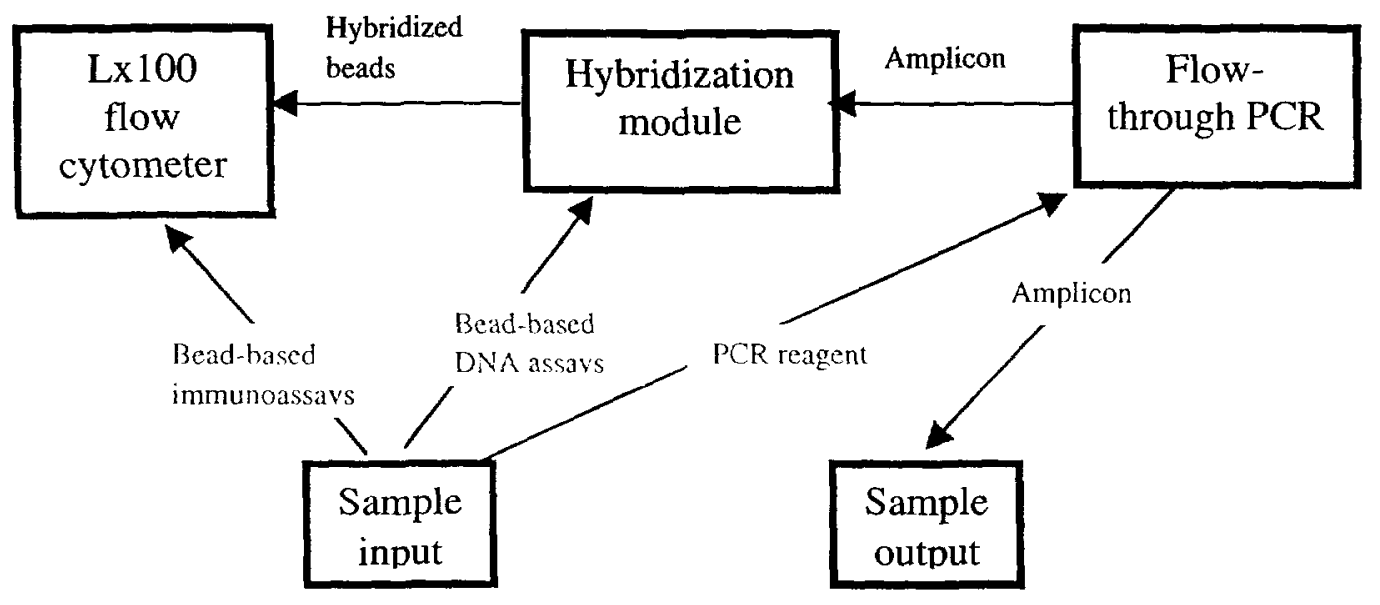




\section{Specifications}

\section{Lx-100 flow cytometer}

The detection platform for the Hybrid is the Luminex 100 flow cytometer. This instrument is capable of differentiating up to 100 different bead assays. The Lx-100 will be used for measuring bead and reporter fluorescence in both multiplex immuno- and oligo-based assays.

\section{Physical}

- size $-3 \mathrm{cu}$. ft.

- weight -30 lbs.

- ruggedness - lab bench

\section{Lx-100 Fluidics}

- syringe pump driven

- sample size $(25 \mu \mathrm{l})$

- internal wash cycle

- self-contained

\section{Mechanical}

- buffer/water reservoir ( $2 \mathrm{~L}$ sheath)

- teflon tubing/interconnects

- syringe sample input $(25-100 \mu \mathrm{l})$

\section{Performance}

- Multiplex detection (simulant $a, b$, etc.)

- Sensitivity - (based on simulant assay)

- Analysis time $-<2$ minutes

\section{Flow-through PCR module}

A new flow-through PCR thermocycler module will replace the current problematic HANAA module. This flow-through PCR device is capable of continuous sample introduction and real time identification using Taqman based fluorescent assays.

\section{Physical}

- size $-0.5 \mathrm{cu}$. ft. (plugs into Global FIA fluidics system)

- weight $-8 \mathrm{lbs}$.

\section{Performance}

- Rapid nucleic acid amplification ( $\sim$ cycle/30 sec)

- Dual channel blue EX, green EM and green Ex, orange Em fluorescent detection optics

- Sensitivity (assay dependent, $\sim 10^{3} \mathrm{cfu} / \mathrm{ml}$ for $\mathrm{Eh}$ ) 


\section{Global FIA Fluidics}

The basic components of the fluidics platform include: a carrier fluid, a syringe pump, a holding coil, a multi-port selection valve, sample input/outputs, a separation cell, and a hybridization chamber. The carrier fluid is used to draw and pump fluids sequentially through the various sample ports on the selection valve. The holding coil prevents contamination of the syringe pump. The selection valve serves as the interface between all components of the fluidics, offering a flexible medium for changing and upgrading the various fluidic components. The hybridization chamber is used to mix and heat the labeled Luminex beads and PCR amplicon during the hybridization reaction. The separation cell is used to separate, wash, and/or preconcentrate the microbeads at various points in the multiplex immunoassay or bead-based DNA assay.

\section{Physical}

- size - 1 cu. ft.

- weight -7 lbs.

\section{Hybridization Module}

- This unit will be redesigned to provide better performance with a $25 \mu l$ sample, including better positioning within the heated volume.

- temperature range $\left(25^{\circ}-95^{\circ}\right)$

- heat $/$ cool rate $-1.5 \mathrm{sec} / \mathrm{deg}$ heating, $30 \mathrm{sec} / \mathrm{deg}$ cooling

- 2 input/output ports per module

\section{Global FIA Fluidics}

- syringe pump driven $(1 \mathrm{ml})$

- variable flow rates $(3-1000 \mu \mathrm{l} / \mathrm{sec})$

- variable sample size (up to $1 \mathrm{ml}$ )

- 2 multi-port selection valves (10- and 14-port)

\section{Mechanical}

- teflon tubing/interconnects

- input sample port (immunossay reagent, PCR reagent, bead assay components, etc.)

- sealed output port for PCR product

- buffer reservoir

- bleach/decontamination reservoir

- waste collection reservoir

- bead sequestration device for washing and preconcentrating $5.5 \mu \mathrm{m}$ Lx beads 


\section{Data Acquistion/Analysis}

Software controls and monitors independently all components of the Hybrid ( Lx 100, PCR module, and Global FIA fluidics) sequentially through a single terminal.

\section{Computer}

- Laptop/ Windows based PC

- $233 \mathrm{MHz}$ or better processor

- $>4$ GB hard drive

- color high resolution display

- >64 MB memory

\section{Communication}

- Luminex 100 - serial comm.

- Flow-through PCR module - DAQ1200 PCMCIA card

- Global FIA/hybridization unit - serial comm.

\section{Software/User Interface}

- National Instruments LabView software

- Single Hybrid graphical users interface (GUI)

- Instrument control of Lx 100 multiplex cytometer

- Control of flow-through PCR module

- Software configured fluidics sequencing

Data acquisition

- User-controlled data storage and set-up 


\title{
TEST PLAN FOR MULTIPLEX PCR PRODUCT IDENTIFICATION WITH THE FIELD DEPLOYABLE PROTOTYPE HYBRID INSTRUMENT
}

\author{
Richard G. Langlois \\ Lawrence Livermore National Laboratory \\ Livermore, CA 94550
}

October 17, 2001

NAS_Hybrid PCR and Multiplex Assay Project

Task 3

\section{Objectives for the Hybrid laboratory trial}

The primary objective of this test plan is to demonstrate that the prototype Hybrid PCR/immunoassay instrument, equipped with LLNL-designed multiplex bead-capture assays, can be used to identify unknown bacterial species when challenged with a series of blind samples.

The approach is for an operator to provide a blind sample mixed with PCR reagents. The Hybrid instrument will then, (1) draw the sample into the flow-through PCR module, (2) amplify the sample in the rapid thermal cycler, (3) transport the PCR product, beads, and other reagents to the hybridization cell, (4) hybridize at elevated temperature, (5) transport the final sample to a LX-100 flow cytometer for flow analysis, (6) and report the results of the analysis on the computer screen. The operator can also initiate a decontamination cycle after positive samples.

\section{Technical Approach}

\section{Trial schedule and format}

The laboratory trial will be performed at LLNL during the first 2 weeks of December, 2001. A total of 8 blind samples will be analyzed sequentially. Since each amplification, analysis, decon cycle may take $\sim 30-60 \mathrm{~min}$, the trial will require one working day.

\section{Samples}

8 coded samples in PCR buffer

Samples consist of 3 blanks, 3 single-agent, and 2 multi-agent samples

Template concentrations will be about 10,000 bacteria./ml

\section{Instrumentation}

The current Hybrid system will be made operational and checked out thoroughly prior to the blind test. This system consists of the HANAA flow-through PCR prototype, the post-PCR hybridization module and fluidics, the Luminex LX-100 flow cytometer and the control computer. The fluidics will also introduce sample and decontamination 
reagents to the cycler. Optical detection will not be used in the blind trial as Taqman probes interfere with the bead assay.

The Hybrid will perform the following functions:

- Amplification in the current HANAA flow-through PCR prototype.

- Post-PCR hybridization with the current Global fluidics system and hybridization cell

- Flow analysis with the attached Luminex LX-100

- Operation under single computer control for PCR, fluidics, Luminex

\section{Assay}

The primary objective is to adapt the direct-capture 3-plex simulant assay so that it can be performed on the completed prototype hybrid instrument. The laboratory trial will test the capability of the hybrid instrument with this assay to correctly identify samples containing B. g., B. t., and E. h. either singly or in combination.

While we have assays for 2 additional real pathogens, B.a. and Y.p., we have not yet received the specialized primers and probes required to adapt these assays to beads. If the reagents arrive, we will explore the possibility of a 5-plex assay.

\section{Assay characteristics:}

PCR amplification will utilize a 3-temperature thermal-cycle profile. (See Appendix below for reagent and thermal cycle conditions)

Multiplex bead assay will utilize a no wash direct capture assay (See Appendix below for the bead capture hybridization protocol)

\section{Summary}

In past reviews we have demonstrated the capabilities of individual components of the prototype hybrid instrument and multiplex bead capture assasy. This laboratory demonstration is designed to test the ability of the prototype hybrid instrument to sequentially perform all required functions for multiplex identification. The use of sequential blind samples will test the ability of the instrument to identify targets singly, and in combination, as well as assess decontamination needs between samples. It is expected that the results obtained with the current assays will be useful in guiding the development of customer-specific multiplex assays in the future.

\section{Appendix}

\section{Reagents and conditions for flow through PCR}

PCR Mix:

1X PCR buffer

$6 \mathrm{mM} \mathrm{MgCl} 2$

$0.2 \mathrm{mM}$ each dNTP

$0.4 \mu \mathrm{M}$ each oligol

$0.25 \mathrm{U} \mathrm{Pt}$ Taq polymerase 
PCR Sample:

$5 \mu$ l sample

$20 \mu \mathrm{l}$ mix

Bacterial templates:

Cells in culture (E.h.)

Spores in culture (B.g., B.t.)

Effective concentration $10^{\wedge} 5 / \mathrm{ml}$

Thermal-cycle Profile:

1 cycle

$96 \mathrm{C} 10 \mathrm{sec}$

40 cycle

$92 \mathrm{C} 10 \mathrm{sec}$

$58 \mathrm{C} 10 \mathrm{sec}$

$70 \mathrm{C} 10 \mathrm{sec}$

Protocol for no wash direct capture assay

No Wash Hybridization

1. Aspirate $5 \mu \mathrm{l}$ of sample

2. Mix with $22 \mu$ l of Bead mix

3. Move to hybridization cell

4. Denature @ $96^{\circ} \mathrm{C}$ for 5 minutes

5 . Incubate@ @ $56^{\circ} \mathrm{C}$ for 5 minutes

6. Add $60 \mu$ l of Streptavidin PE $(4 \mathrm{ng} / \mu \mathrm{l})$

7. Incubate @ room temperature for 10 minutes

8. Read in the Luminex. 